\title{
Rancang Bangun Sistem Pengontrol Intensitas Cahaya pada Ruang Baca Berbasis Mikrokontroler ATMEGA16
}

Maulidan Kelana1), Abdul Muid*1), Nurhasanah1)

\author{
1Program Studi Fisika, Fakultas Matematika dan Ilmu Pengetahuan Alam \\ Universitas Tanjungpura Pontianak, Indonesia \\ *Email : muidssi@yahoo.com
}

\begin{abstract}
Abstrak
Telah dilakukan pembuatan sistem pengontrol cahaya untuk mengontrol kuat penerangan cahaya pada ruang baca. Sistem ini dibangun menggunakan sensor Light Dependent Resistor (LDR) sebagai pendeteksi intensitas cahaya. Tegangan analog LDR diolah oleh mikrokontroler ATMega16untuk mengontrol tiga buah lampu sebagai sumber penerangan ruang baca. Pengujian dilakukan dengan membandingkan hasil pengukuran intensitas cahaya alat hasil rancangan denganalat standar. Hasil penelitian ini menunjukkan bahwa sistem dapat mengontrol dan menjaga kestabilan intensitas cahaya ruang baca dalam rentang 300-400Lux.
\end{abstract}

Kata kunci:Sensor LDR, Intensitas Cahaya, mikrokontroler ATMega16.

\section{Latar Belakang}

Membaca merupakan salah satu aktivitas yang memerlukan cahaya. Intensitas cahaya yang direkomendasikan dalam aktivitas membaca yaitu tidak kurang dari 250 Lux (SNI No. 16-7062-2004). Berdasarkan penelitian yang telah dilakukan Fathimahhayati (2012) dan Nursalim dkk (2012) menyatakan bahwa sebagian besar intensitas penerangan cahaya pada ruang tempat berlangsung aktivitas membaca tidak sesuai SNI (Standar Nasional Indonesia). Intensitas cahaya yang tidak sesuai standar dalam proses membaca dapat menjadi salah satu penyebab kerusakan organ penglihatan.

Penelitian tentang kontrol intensitas cahaya telah banyak dilakukan seperti Novianti dkk (2012) membuat perancangan prototipe sistem penerangan otomatis ruangan berjendela berdasarkan intensitas cahaya dengan mengontrol dimer lampu pijar sebagai sumber penerangan. Otomo dkk (2013) membuat sistem kontrol penyalaan lampu ruang berdasarkan pendeteksian ada tidaknya orang di dalam ruangan. Dari penelitiannya didapatkan bahwa lampu dapat menyala secara otomatis berdasarkan keberadaan orang di dalam ruangan menggunakan sensor Passive Infra-Red (PIR). Tarigan (2013) merancang pengontrolan lampu menyala menyesuaikan intensitas cahaya sekitar. Penelitian-penelitian tersebut menunjukkan bahwa dapat dibuat alat yang dapat mengontrol intensitas cahaya ruang baca. Pengontrolan pada ruang tersebut akan menghasilkan kuat penerangan cahaya standar yang sesuai kebutuhan dalam proses membaca.

Pada penelitian ini dirancang sebuah sistem pengontrol intensitas cahaya pada ruang baca dengan mengontrol tiga buah lampu yang digunakan sebagai sumber penerangan ruang tersebut. Intensitas cahaya pada ruang baca yang dipengaruhi intensitas cahaya dari lingkungan akan dikontrol hingga intensitas cahaya tersebut sesuai dengan intensitas cahaya standar yang telah ditentukan. Sistem ini menggunakan sensor LDR dan mikrokontroler ATMega16. Seluruh aktivitas pengontrolan sistem dilakukan oleh mikrokontroler ATMega16. Sensor LDR akan mengirimkan data intensitas cahaya ke mikrokontroler yang kemudian akan melakukan penyesuaian intensitas cahaya standar dengan melakukan pemutusan dan penyambungan daya listrik ke lampu sesuai besarnya intensitas cahaya lingkungan. Keunggulan ATMega16 yaitu memiliki waktu eksekusi program yang relatif cepat dan memiliki konsumsi daya rendah terhadap kecepatan proses eksekusi perintah (Andrianto, 2008). Sedangkan LDR banyak digunakan karena mempunyai ukuran kecil, murah dan memiliki sensitivitas tinggi (Budiharto dkk, 2005).

\section{Metodologi}

Waktu yang diperlukan dalam pembuatan alat ini adalah 6 bulan yaitu dari bulan April 2014 sampai dengan bulan Agustus 2014. Lokasi pelaksanaan penelitian dilaksanakan di Laboratorium Fisika Lanjut FMIPA Universitas Tanjungpura.

\subsection{Perancangan Sistem}

Diagram blok perancangan sistem dari alat ini dapat dilihat pada Gambar 1.

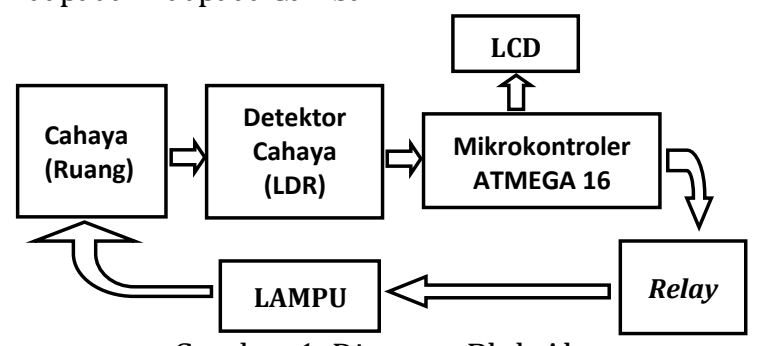

Gambar 1. Diagram Blok Alat 
Cara kerja dari sistem ini berdasarkan Gambar 1 yaitu sinar yang datang akan terdeteksi oleh LDR dan membuat perubahan resistansi sesuai dengan besarnya sinar yang datang pada LDR tersebut. Perubahan resistansi tersebut dijadikan sebagai parameter fisis dalam pengukuran intensitas cahaya. Resistansi LDR dikonversi menjadi input sinyal analog dan diproses oleh ADC pada mikrokontroler dalam bentuk data digital yang ditampilkan pada LCD. Kemudian mikrokontroler akan memproses sinyal-sinyal yang diperoleh melalui perintah yang telah ditanam didalamnya dan mengontrol lampu sehingga kuat penerangan cahaya menjadi terkontrol.

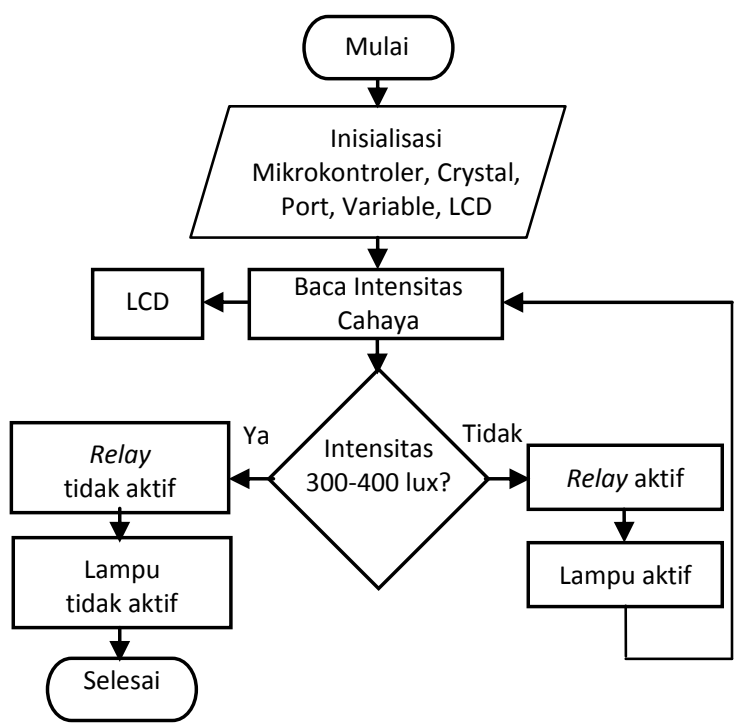

Gambar 2. Diagram Alur Kerja Sistem

Diagram alur kerja sistem pada Gambar 2 menggunakan intensitas cahaya ideal sebagai intensitas cahaya referensi dalam rentang 300400 Lux. Relay dan Lampu dikontrol berdasarkan intensitas cahaya referensi tersebut, sehingga intensitas cahaya referensi tersebut menentukan kondisi intensitas cahaya ruang baca.

\subsection{Perancangan Prototipe}

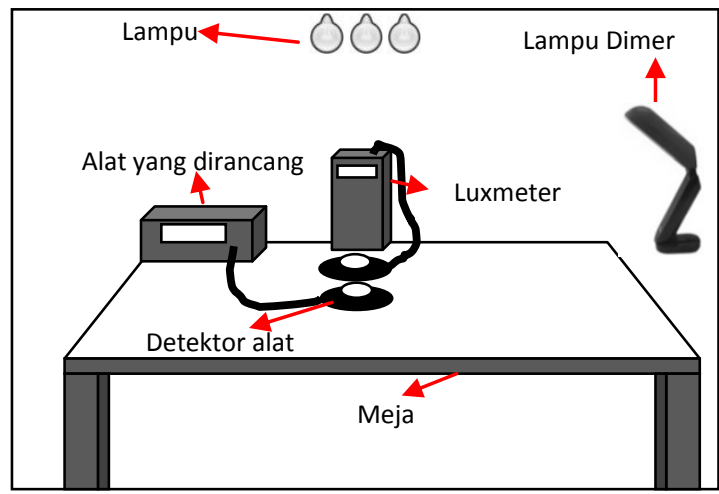

Gambar 3. Desain Instalasi Sistem

Seperti ditunjukkan pada Gambar 3, tiga buah lampu diletakkan pada posisi atas secara berdampingan, dimana ketiga lampu ini berperan sebagai pengontrol intensitas cahaya di dalam ruang baca. Sebuah lampu dimer diletakkan di samping meja yang berperan sebagai intensitas cahaya tambahan dari lingkungan dimana lampu dimer ini digunakan sebagai pengganti intensitas cahaya alami lingkungan dan sistem pengontrol diletakkan dibawah lampu pengontrol.

\subsection{Perancangan Perangkat Keras Sistem}

Perancangan perangkat keras dalam sistem pengontrol intensitas cahaya pada ruang baca berbasis ATMega16 meliputi perancangan sensor cahaya, driver relay dan display LCD. Gambar 4 adalah gambar rangkaian keseluruhan dari sistem pengontrol intensitas cahaya pada ruang baca berbasis ATMega16.

Mikrokontroler yang digunakan dalam sistem pengontrol intensitas cahaya ini adalah ATMega16. Penggunaan ATMega16 karena mudah didapat dipasaran dengan harga yang terjangkau dan memiliki fitur yang lengkap.Konfigurasi pin ATMega16 dengan kemasan 40 pin Dual In-line Package (DIP) dapat dilihat pada Gambar 5.

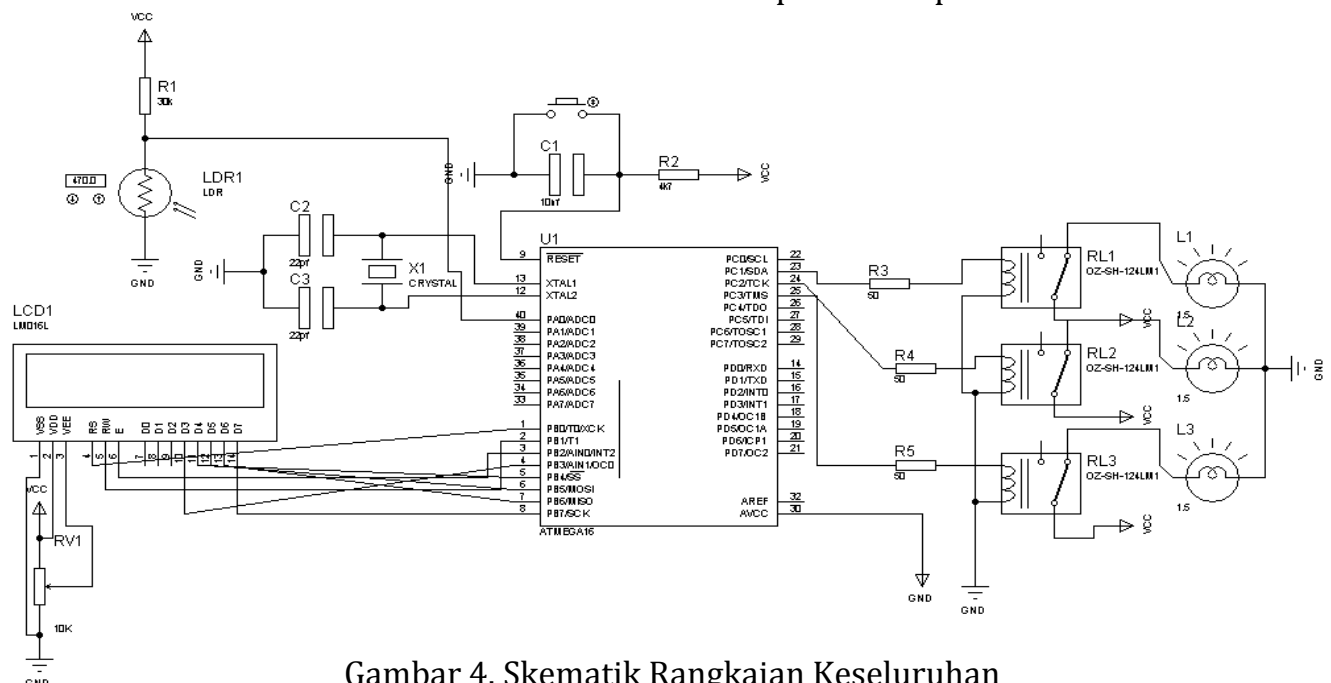




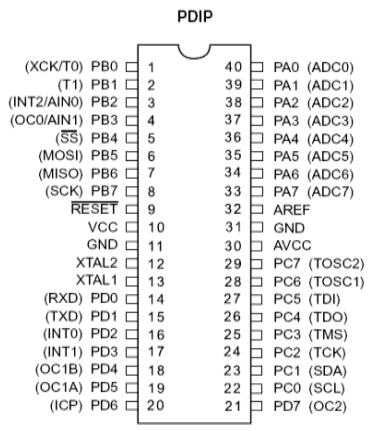

Gambar 5. Konfigurasi Kaki (pin) ATMega16

(Sumber: Andrianto, 2008)

Adapun rincian pemakaian port pada mikrokontroler sistem pengontrol intensitas cahaya pada ruang baca berbasis ATMega16 ini adalah sebagai berikut :

1. PORTA.0 dihubungkan kebagian sensor Cahaya LDR

2. PORTB.0 sampai PORTB.5 dihubungkan kebagian display LCD

3. PORTC.1, PORTC.2 dan PORTC.3 dihubungkan kebagian driverrelay.

\subsection{Perancangan Sensor}

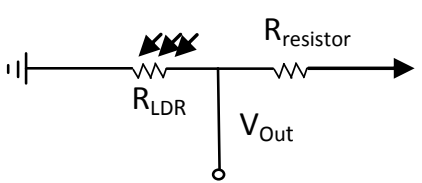

Gambar 6. Rangkaian Sensor

Dari Gambar 6 dapat dicari tegangan Output:

$$
V_{\text {out }}=\frac{R_{L D R}}{R_{\text {esistor }+R_{L D R}}} V_{c c}(1)
$$

Sensor cahaya pada sistem ini digunakan sebagai rangkaian pembagi tegangan. Tegangan output rangkaian akan dipengaruhi oleh perubahan resistansi LDR akibat perubahan intensitas cahaya.

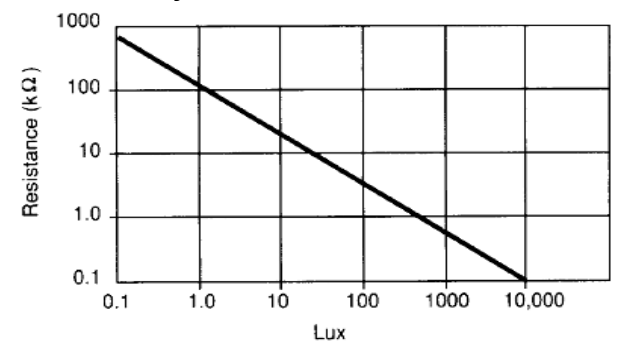

Gambar 7. Grafik hubungan antara resistansi dan iluminasi (Sumber: data sheet LDR)

Dari Gambar 7 diketahui bahwa hubungan antara resistansi LDR dan iluminasi berupa grafik nonlinier.

\subsection{Perancangan Perangkat Lunak}

Perangkat lunak menggunakan bahasa $\mathrm{C}$ dalam penulisan programnya, karena dapat mempermudah dan mempersingkat instruksiintruksi yang digunakan dalam bahasa assembly.
Dalam pembuatan program digunakan fungsi atau aritmatika. Untuk penulisan program digunakan perangkat lunakAVR Studio. Program yang telah ditulis dalam bahasa $\mathrm{C}$ di-compile oleh AVR Studio dan menghasilkan beberapa file yang akan digunakan untuk ditanamkan ke mikrokontroler. Proses penanaman program ke IC mikrokontroler AVR dapat menggunakan sistem download secara In-System Programming (ISP) dengan bantuan AVR Studio. ISP Flash Onchip mengijinkan memori program untuk diprogram ulang dalam sistem menggunakan hubungan serial SPI.

\section{Hasil dan Pembahasan}

Proses pembuatan perangkat keras dilakukan dalam satu board utama dengan sensor cahaya yang fleksibel agar bisa bebas diarahkan. Gambar 8 adalah gambar dari hasil pembuatan bagian perangkat keras sistem pengontrol intensitas cahaya.

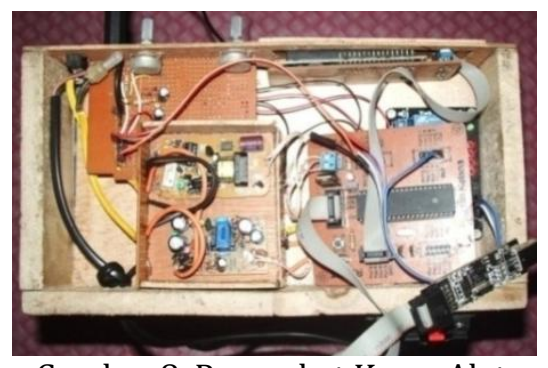

Gambar 8. Perangkat Keras Alat

Pada board utama terdapat beberapa blok yang berfungsi sebagai penunjang kerja sistem, sehingga diperlukan pengujian setiap bagian dari blok tersebut.

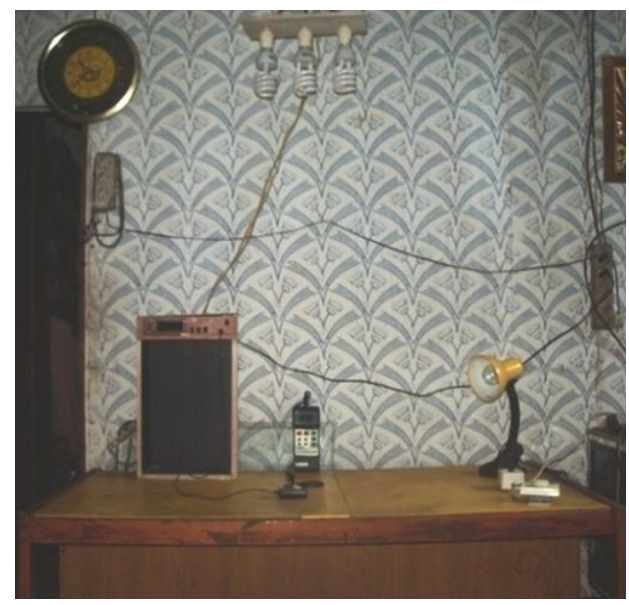

Gambar9. Instalasi Alat pada Ruang Baca

Setelah proses perancangan dan pembuatan alat dilakukan, langkah selanjutnya adalah melakukan proses pengujian dan analisa data dari setiap blok diagram yang telah dibuat. Proses pengujian tersebut meliputi pengujian mikrokontroler dan LCD, pengujian Relay, pengujian Lampu dan pengujian sistem secara keseluruhan. 
Untuk mengetahui sistem bekerja dengan baik atau tidak, maka dilakukan pengujian instalasi dengan mengalirkan arus listrik ke tiga buah lampu dan alat yang telah dibuat seperti Gambar9. Pengaturan posisi ketiga lampu dan penempatan sensor sangat penting dalam penelitian ini, karena ketiga lampu tersebut akan menjadi sumber penerangan dalam mengontrol intensitas cahaya ruang baca.

Penempatan sensor cahaya LDR pada posisi bagian atas meja dilakukan agar titik pengukuran cahaya terukur sesuai batasan intensitas cahaya yang telah ditentukan. Sumber cahaya berasal dari tiga buah lampu berdaya 35 Watt dengan kemampuan 1890 Lumen.

\subsection{Pengujian Mikrokontroler ATMega16 dan LCD 16x2}

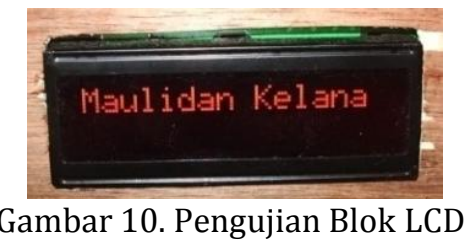

Pengujian mikrokontroler dapat dilakukan dengan melakukan pengunduhan salah satu program. Jika program tersebut dapat berjalan dengan lancar maka dipastikan mikrokontroler dapat digunakan. Pengujian mikrokontroler dilakukan dengan melakukan pengunduhan program LCD 16x2. Dalam proses pengujian blok LCD diperlukan kode program yang diunduhkan pada mikrokontroler. Kode program yang dibuat adalah program yang berfungsi untuk menampilkan tulisan yang hasilnya dapat dilihat pada Gambar 10.

\subsection{Pengujian Sensor Cahaya LDR}

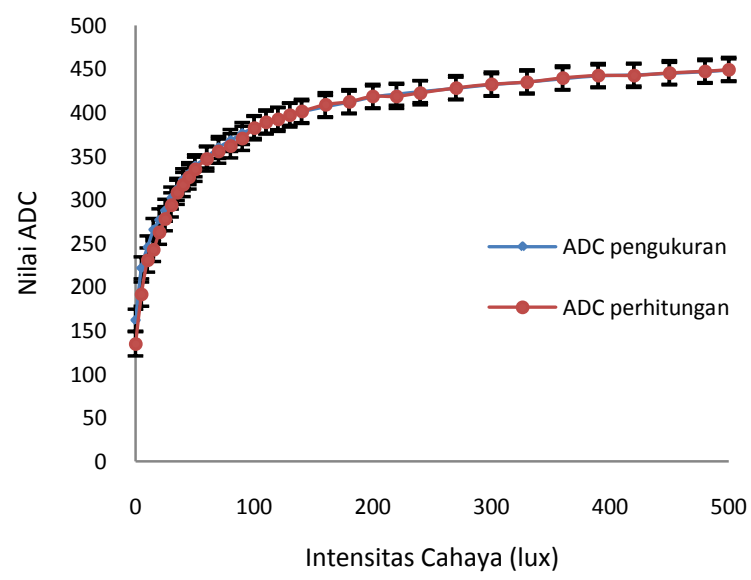

Gambar 11. Grafik Hasil Pembacaan Intensitas Cahaya dan Luxmeter

Proses pengujian sensor LDR dilakukan dua tahap, yaitu mengukur perubahan resistansi LDR terhadap intensitas cahaya secara manual dan mengukur data intensitas cahaya yang ditampilkan oleh alat yang dirancang. Tujuan pengujian ini yaitu untuk mengetahui apakah sensor LDR membaca intensitas cahaya dengan baik dan dapat digunakan dalam pembuatan sistem pengontrol cahaya.

Berdasarkan Gambar 11, diketahui bahwa proses pembacaan intensitas cahaya oleh alat berfungsi baik dan memiliki error relatif 2,04\%. Adanya error pembacaan intensitas cahaya ini, dapat disebabkan oleh resistansi perangkat dan faktor sampling pada proses pembacaan intensitas cahaya kedua sensor.

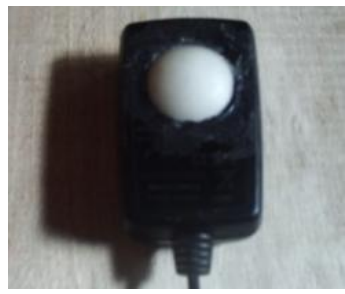

Gambar 12. Bentuk fisik detektor cahaya

Bentuk detektor dirancang dengan bentuk seperti pada Gambar 12 dengan maksud agar mudah memposisikan sensor LDR untuk memperoleh data intensitas cahaya. Pada bagian sensor ditutupi dengan tutup setengah bola yang bertujuan untuk mengurangi intensitas cahaya yang masuk. Intensitas cahaya yang akan dideteksi oleh sensor LDR harus dikurangi karena tanggapan sensor LDR secara langsung (tanpa tutup) pada rentang intensitas cahaya 300-400 Lux memiliki rentang nilai perubahan resistansi yang relatif kecil. Sehingga dengan membuat sensor LDR seperti Gambar 12 diharapkan memperoleh rentang nilai perubahan resistansi yang relatif lebih besar.

\subsection{Pengujian Lampu}

Lampu yang digunakan untuk memperoleh intensitas cahaya yang telah ditentukan pada penelitian ini yaitu tiga buah lampu Neon 35 Watt dengan kemampuan 1890 Lumen. Lampu tersebut dipilih dengan menyesuaikan intensitas cahaya yang diperlukan untuk penerangan pada ruang baca. Dengan demikian kebutuhan intensitas cahaya pada ruangan dapat dikontrol dengan ketiga lampu tersebut.

Tabel 1. Pengujian Lampu

\begin{tabular}{ccc}
\hline Lampu & $\begin{array}{c}\text { Kuat Penerangan } \\
\text { (Lux) }\end{array}$ & $\begin{array}{c}\text { Nilai } \\
\text { ADC }\end{array}$ \\
\hline A & 98 & 346 \\
B & 104 & 355 \\
C & 97 & 347 \\
A+B & 202 & 396 \\
A+C & 205 & 369 \\
B+C & 209 & 398 \\
$A+B+C$ & 300 & 417 \\
\hline
\end{tabular}




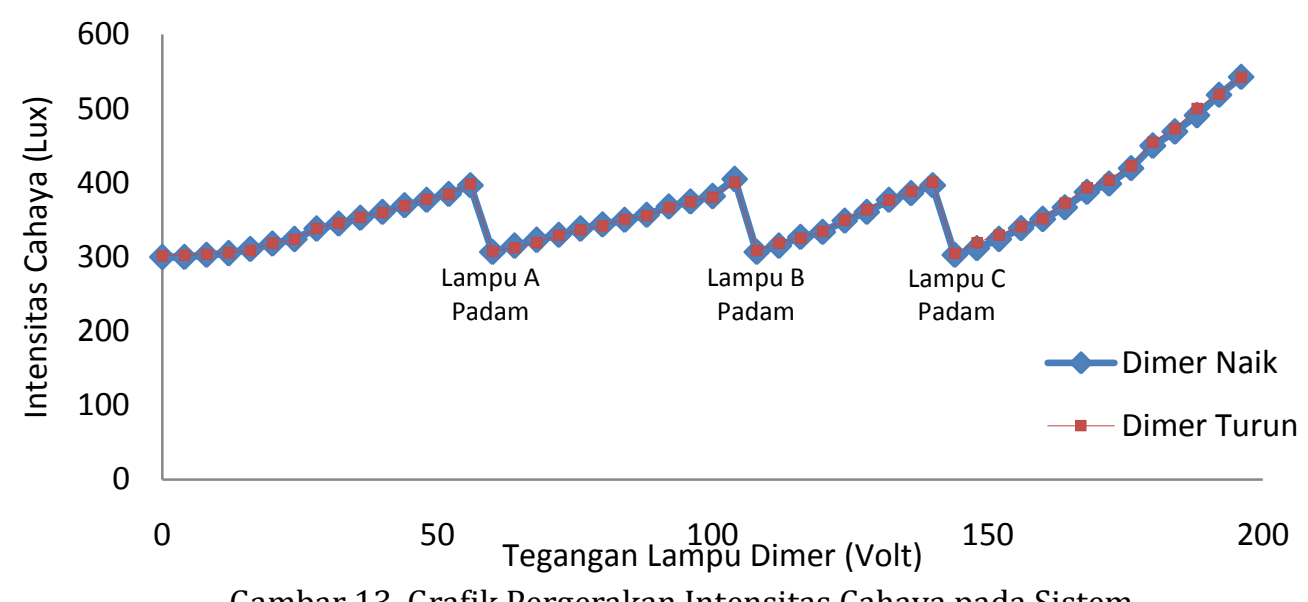

Dari tabel 1 dapat diketahui bahwa intensitas cahaya yang dihasilkan dari tiga buah lampu Neon tersebut dapat memberikan kontribusi penerangan cahaya sesuai standar untuk sistem pada penelitian ini.

\subsection{Pengujian Driver Relay}

Pengujian driver relay dilakukan untuk mengetahui apakah lampu telah terhubung dengan mikrokontroler ATMega16. Pengujian driver relay dilakukan dengan cara memprogram mikrokontroler untuk menghidupkan ketiga lampu secara bergantian. Jika lampu menyala sesuai program yang ditanamkan, maka driver relay berfungsi baik.

\begin{tabular}{ccc}
\multicolumn{3}{c}{ Tabel 2. Pengujian Driver Relay } \\
\hline \multirow{2}{*}{ Relay } & $\begin{array}{c}\text { Perintah } \\
\text { Program }\end{array}$ & $\begin{array}{c}\text { Kondisi } \\
\text { Relay }\end{array}$ \\
\hline \multirow{2}{*}{ Relay 1} & On & terhubung \\
& Off & Tidak \\
Relay 2 & On & terhubung \\
& Off & Tidak \\
Relay 3 & On & terhubung \\
& Off & Tidak \\
\hline
\end{tabular}

Berdasarkan tabel 2, dapat disimpulkan bahwa rangkaian driver relay yang dibuat berjalan atau berkerja sesuai dengan yang diinginkan.

\subsection{Pengujian Sistem Secara Keseluruhan}

Pada data dimer naik, tegangan awal dimer 0 Volt (sistem gelap) ketiga lampu menyala dan intensitas cahaya sistem berubah menjadi 300 Lux. Ketika dimer dinaikkan secara bertahap, intensitas cahaya sistem berubah mengikuti intensitas cahaya lampu dimer. Pada saat tegangan dimer 60 Volt, lampu A padam sehingga intensitas cahaya sistem turun hingga 309 Lux. Tegangan lampu dimer dinaikkan terus bertahap hingga lampu B dan $\mathrm{C}$ juga padam seperti peristiwa lampu A. Ketika lampu A, B dan C padam (pada tegangan dimer 108 Volt), yang menyala hanya lampu dimer dan intensitas cahaya lingkungan sistem berubah mengikuti intensitas cahaya lampu dimer tersebut.

Pada data dimer turun, terjadi peristiwa serupa seperti pada data dimer naik. Yang berbeda hanya tegangan lampu dimer diturunkan dari awal yaitu tegangan dimer paling tinggi (196 Volt) hingga tegangan dimer paling kecil (0 Volt). Hasil pengujian sistem pengontrol intensitas cahaya secara keseluruhan seperti ditunjukkan pada Gambar 13, didapatkan bahwa pergerakan intensitas cahaya dalam sistem dengan setting program yang ditanamkan di dalam mikrokontroler dapat mengontrol ketiga lampu dan menjaga kestabilan intensitas cahaya dalam rentang 300400 Lux.

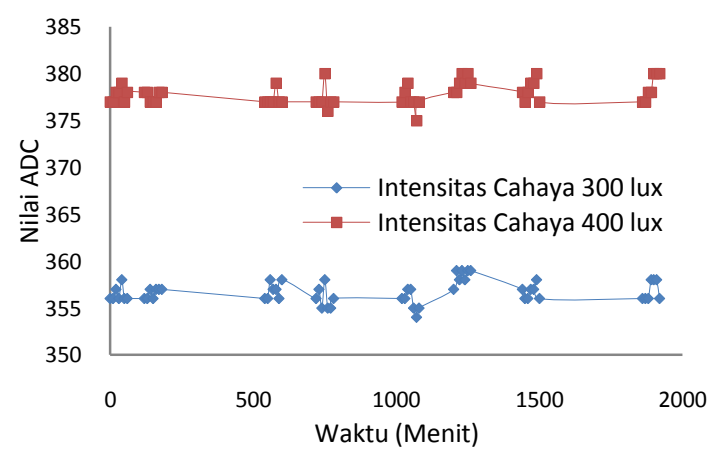

Gambar 14. Grafik Pembacaan Intensitas Cahaya terhadap Waktu

Dari grafik pada Gambar 14, didapatkan bahwa pergerakan intensitas cahaya yang dibaca oleh alat yang dirancang pada pengukuran intensitas cahaya setiap waktunya, stabil dengan nilai error relatif sebesar 0,27\% untuk pengukuran intensitas cahaya 300 Lux dan $0,25 \%$ untuk pengukuran intensitas cahaya 400 Lux. Adanya error pembacaan intensitas cahaya ini, dapat disebabkan oleh resistansi perangkat yang dipengaruhi suhu sistem dan faktor sampling pada proses pembacaan intensitas cahaya sensor. 


\section{Kesimpulan}

Berdasarkan penelitian ini, telah dilakukan perancangan, pembuatan, pengujian serta analisis sistem pengontrol intensitas cahaya dan dapat disimpulkan bahwa:

1. Hasil pengujian menunjukkan bahwa sistem dapat mengontrol ketiga lampu dan menjaga kestabilan intensitas cahaya ruang baca dalam rentang 300-400 Lux dengan error relatif alat sebesar 2,04\%.

2. Pembacaan intensitas cahaya oleh alat stabil terhadap waktu dengan error relatif sebesar $0,27 \%$ untuk pengukuran intensitas cahaya 300 Lux dan $0,25 \%$ untuk intensitas cahaya pengukuran $400 \mathrm{Lux}$.

\section{Daftar Pustaka}

Andrianto, H., 2008, Pemrograman Mikrokontroler AVR ATMega16, Penerbit INFORMATIKA, Bandung.

Anonym, 1997, Data sheet Light Dependent Resistors, RS Components, Corby, Northants.

Budiharto, W., dan Firmansyah, S., 2005, Elektronika Digital Dan Mikroprosesor, Penerbit ANDI, Yogyakarta.

Fathimahhayati, L. D., 2012, Analisis dan Evaluasi Faktor Pencahayaan pada Ruang Kuliah (Studi Kasus di Jurusan Teknik Mesin Dan Industri Universitas Gadjah Mada Yogyakarta), Jurnal Angkasa.

Naskah Standar Nasional Indonesia (SNI) No 167062-2004, Pengukuran Intensitas Penerangan di Tempat Kerja, Jakarta.

Novianti, K., Lubis, C., dan Tony, 2012, Perancangan Prototipe Sistem Penerangan Otomatis Ruangan Berjendela berdasarkan Intensitas Cahaya, Seminar Nasional Teknologi Informasi.

Nursalim, Kurniati, S., dan Kabelen, A., 2013, Pengujian Intensitas Cahaya pada Ruang Laboratorium Komputer Fakultas Sains Dan Teknik (FST) Undana Menggunakan Calculux V.5.0, Jurnal Media Elektro.

Otomo, G., dan Wildian, 2013, Sistem Kontrol Penyalaan Lampu Ruang berdasarkan Pendeteksian ada Tidaknya Orang di dalam Ruangan, Jurnal Fisika Unand Vol. 2, No. 4.

Tarigan, P., 2013, Perancangan Alat Simulator Kontroler Lampu Rumah Berbasis Komputerisasi dengan Menggunakan Metode Fuzzy Logic Control,Pelita Informatika Budi Darma, Volume III. 